\title{
Parents, Identities, and Trajectories of Antisocial Behavior from Adolescence to Young Adulthood
}

\author{
Wendi L. Johnson ${ }^{1} \cdot$ Peggy C. Giordano ${ }^{2}$. \\ Monica A. Longmore ${ }^{2}$. Wendy D. Manning ${ }^{2}$
}

Received: 29 February 2016 /Revised: 15 July 2016 / Accepted: 9 September 2016 /

Published online: 12 October 2016

(C) Springer International Publishing AG 2016

\begin{abstract}
Purpose Assessments of young adult well-being often focus on family formation and employment experiences, and ignore the potentially important, continuing role of parents. We consider whether and how parental influence reaches beyond the adolescent years.

Methods Drawing on longitudinal data from the Toledo Adolescent Relationships Study (TARS) $(N=1242)$ and multilevel modeling, analyses examine direct and indirect ways that traditional parenting practices, as well as parental histories of problematic behavior influence trajectories of offspring antisocial behavior.

Results Parental antisocial experiences influenced young adult outcomes and operated through youths' own developing identities. Youths whose parents scored higher on an index of antisocial behavior were more likely to agree with partier and troublemaker labels. Traditional parenting factors, such as parental support and harsh parenting also influenced respondents' own trajectories of antisocial behavior. Thus, parental influence persisted net of young adult gainful activity (school, employment), parenthood, and intimate involvement.

Conclusions The results of the current study highlight that parent-child relationships and their association with antisocial behavior remains fluid and dynamic well into adolescence and young adulthood. Parents are also implicated in the adoption of problematic identities which in turn are associated with antisocial behavior. Taken together, greater attention should be given to how parents shape and influence the trajectories of behavior among their adolescent and young adult offspring.
\end{abstract}

Wendi L. Johnson

wljohnson@oakland.edu

1 Department of Sociology, Anthropology, Social Work and Criminal Justice, Oakland University, Rochester, MI 48302, USA

2 Department of Sociology, Bowling Green State University, Bowling Green, OH 43403, USA 
Keywords Delinquency· Emerging adulthood Parenting $\cdot$ Longitudinal

\section{Introduction}

It is well accepted that parents provide a critical foundation for their children's behavior. Parents who effectively establish a strong bond with their children early in life foster children's capacities to develop strong, healthy, and prosocial bonds with others across adolescence and into adulthood [13, 30]. In contrast to the prosocial benefits provided by attachment, harsh parenting has been linked to a host of deleterious outcomes including antisocial behavior [62]. Thus, attachment and harsh parenting represent distinct forces (support and coercive control) that exemplify the quality of the parent-child social bond and independently influence antisocial behavior. Although parent-child bonds likely demonstrate a great deal of continuity over time, variations in the quality of the parent-child relationship may occur [7]. Erosion or improvement in the parent-child bond, as well as changes over time in parenting practices themselves may differentially influence the child's behavior. Parents' antisocial histories are also important to consider, and current theoretical treatments have suggested further that traditional parenting measures, such as those described above (e.g., attachment), may condition the effects of parents' antisocial tendencies on offspring behavior [11]. However, given that identity development is a key adolescent developmental task, another possibility is that parents' antisocial histories influence identity formation in their offspring, which in turn influences antisocial behavior.

In the current study we draw on longitudinal data from the Toledo Adolescent Relationships Study (TARS) to focus on how parental factors influence their children's trajectories of antisocial behavior from adolescence through to the less wellresearched period of young adulthood. Specifically, we examine the influence of parents' own early involvement in delinquency, level of attachment to children, and harsh parenting practices on their children's trajectories of antisocial behavior. We also assess whether parents' delinquency influences trajectories of antisocial behavior directly or indirectly through identity processes. Parents' self-reported delinquency during adolescence is assessed at wave 1, while respondents' reports of attachment, harsh parenting, and their endorsement of specific identities such as "partier" and "troublemaker" are time-varying measures assessed at each of the five waves. Our analyses consider the following: (1) Does parents' delinquency distinguish between offspring's trajectories of antisocial behavior; (2) Do improvements in attachment and declines in harsh parenting correspond to within-person change in trajectories of antisocial behavior, controlling for unmeasured heterogeneity among youths; and (3) Do parents' own early involvement in delinquency influence antisocial behavior indirectly through children's adoption of antisocial identities (troublemaker, partier)? As noted by Loeber and Farrington [39], longitudinal designs offer advantages, such as tracing developmental sequences and examining processes of continuity and discontinuity in deviant behaviors. Furthermore, TARS' accelerated cohort design is an asset here, in that it enables us to examine the full span of adolescence and young adulthood (13-28 years of age) across a period of 11 years with only a few waves of data ([59], p. 139). 


\section{Background}

\section{The Parent-Child Bond and Antisocial Behavior}

Numerous studies have examined the influence of parents during early childhood and adolescence on their children's emotional and behavioral outcomes, including antisocial behavior. Particularly notable within criminology is Hirschi's [30] control theory, which posits that strong feelings of attachment to parents create a meaningful bond that the child would not wish to jeopardize by engaging in delinquent or other problem behaviors. Furthermore, the parent-child bond is seen as predictive of the ability to establish attachment to other prosocial relationships (e.g., peers, school, intimate partners) as the child moves into adolescence and young adulthood [14, 26]. Such prosocial relationships are viewed as protective against antisocial behavior.

Additional work focuses on the association between family structure and delinquency and suggests that parents' primary role during adolescence is controlling access to deviant peer networks through supervision [5, 43]. However, Demuth and Brown [18] found that parenting factors mediate the influence of family structure on delinquency, with parental attachment operating as a stronger protector than supervision. Similarly, Warr [67] found that adolescents who are close to parents are less likely to acquire delinquent friends.

Coercive parenting practices are theorized to be associated with increased antisocial behavior in several ways. First, social learning perspectives suggest that parenting practices that include physical punishment may serve as a model for subsequent aggression in children [16]. Additionally, discipline that is inconsistent and overly punitive may inhibit parental efforts to instill sufficient self-control thereby compromising efforts to promote conforming and prosocial behaviors [26]. Other theoretical perspectives have highlighted the potential of coercive exchanges to escalate and become entrenched [61], thereby producing negative emotions including anger [3].

In summary, attachment and harsh parenting (i.e., support and coercion) are often viewed as cornerstones of parenting, with attachment pulling youth away from crime, and harsh parenting pushing them towards crime [15]. Thus, high levels of support accompanied by low levels of coercion are viewed as the optimal scenario and least likely to be associated with antisocial behavior. There are two limitations to this approach. First, this tradition has focused primarily on parents' early, formative role, an emphasis that does not take into account the degree to which parent-child relationships and parenting practices may change over time. Second, this exclusive focus on support and control fails to account for parents' own antisocial history, which may directly influence child behavior, and in turn may shape social interactions between parent and child. Such social interactions may either directly or indirectly influence antisocial behavior among offspring [22].

\section{Building on the Foundation of Early Parent-Child Bonds: Parenting and Antisocial Behavior over Time}

Although extensive studies have examined crime and delinquency during the adolescent period, considerably less work has focused on the transition from 
adolescence to young adulthood [12]. Thus, there is a need to examine the developmental patterns associated with this period, how they shape parent-child interaction, and ultimately influence trajectories of antisocial behavior. The developmental tasks associated with early adulthood have typically included completing formal education, launching a career, and establishing an independent residence and family of one's own [54]. Criminology has focused almost exclusively on marriage and employment as positive influences on desistance from crime. Laub and Sampson $[35,36]$ have argued that the institution of marriage provides informal social controls that promote prosocial behaviors and work against continued adult criminality. Specifically, these informal controls provide turning points and work in concert with available social capital to explain declines in criminality that occur within the adult life course. Laub and Sampson found that as social capital accrues through investment in prosocial activities and relationships associated with work and marriage, the more individuals have to lose by engaging in antisocial behaviors. Thus, the theoretical emphasis is similar to Hirschi's early depiction of the role of informal social control, but the referent shifts away from early familial dynamics to the more adult concerns of marriage and ties to the economic system.

While acknowledging the contributions of the scholarly work described above to our understanding of adolescent delinquency and offending versus desistance in adulthood, a gap remains with respect to explaining the mechanisms associated with transitioning from adolescence to early adulthood and patterns of offending during this stage of the life course. Although criminologists have focused on the benefits of marriage, parenthood, and employment as predictors of desistance through the acquisition of social capital, the median age of first marriage in the USA is 29 for men and 27 for women (United States Census Bureau 2016). Additionally, recent work has highlighted selection processes into marriage suggesting that those with the most resources and least debt are more likely to marry relative to their more socioeconomically disadvantaged peers $[1,2]$. Thus, marriage as a form of social capital associated with deterrence from crime is not a universally experienced transition event for many young adults. Even as many young people choose cohabitation as a prelude or replacement to marriage, recent work suggests that cohabitation may not offer the same protective effects as marriage [55].

Similar to marriage, the age for first birth among mothers in 2013 was 26, representing an all-time national high [44]. Meanwhile, the number of births to teenage mothers has seen a long-term decline over the last seven decades [41]. Consequently, parenthood is an event that is increasingly reserved for later in the life course.

Finally, unemployment rates for those aged 20-24 hover around 10\%, with young people of color disproportionately affected (United States Department of Labor 2016). Hamilton and Hamilton [27] note that young people tend to display high rates of mobility in their employment endeavors, but it is not clear whether this represents deliberate exploration or unintentional floundering. Arnett [8] argues that employment during adolescence is primarily a means of earning extra money to spend in pursuit of leisure activities, but as young people transition to adulthood, work takes on greater meaning as they consider how it will impact their lives long term. Delays in marriage and childbirth may result in young adults feeling less pressure to commit early to careers, favoring instead an exploration of a variety of 
occupational pursuits in an effort to find a good match to their individual interests and skills [9]. Consequently, employment may not operate as a significant source of social capital in ways that characterized earlier eras when the transition to adulthood was more straightforward.

The trends outlined above highlight that variations exist in acquiring the social capital associated with traditional sources of informal social control. Against this backdrop, it is intuitive to consider the potential of parents as continuing sources of reference and influence. While the parent-child bond established in early childhood serves as an important foundational base, parent-child relationships continue to develop and are also subject to change as individuals mature into adulthood [7]. Consequently, parents may serve to fill the gap and continue to be influential as offspring navigate this key and increasingly uncertain transition period. Emotional, identity, and material support from parents may operate as a specific set of resources that decrease involvement in antisocial behavior across adolescence and into adulthood. Prior work has argued that delinquency increases in adolescence as parental influence wanes and peer influence increases [32]. However, a less considered notion is that additional changes in parental influence may affect the nature of the adolescent to adult transition, or that these variations are related to parents' own behavioral backgrounds or orientations.

Aquilino's [7] prospective study showed that while parent-child relationships show some dependence on previous patterns of interaction, they also continue to develop over time. Consistent with developmental theories of individuation, Aquilino argues that parents respond to shifting expectations regarding their offspring's need for autonomy and independence. Thus, from this perspective, while parental monitoring of children's movements and peer relations are paramount during early adolescence, this becomes less salient as children move closer and into young adulthood. Furthermore, consistent with Moffitt's [47] theorizing of adolescence-limited delinquency, peer influence is likely to wane post-graduation. While some youth may suffer limitations in terms of accessing the traditional adult status roles that help foster movement away from delinquency, reaching the age of majority still brings with it increased opportunities and experiences not available during the high-school years [23]. Meanwhile, relationships between parents and their children become more peer-like, defined by mutual respect, affection, and humor [7]. Even among youth who previously engaged in delinquent behaviors and experienced strained relationships with parents during adolescence, adulthood brings greater perspective as youth gain greater appreciation for their parents' own experiences and the importance of familial ties in general [23].

While prior research has highlighted the importance of harsh parenting as a predictor of antisocial behavior [51, 57], most of the research has focused on early childhood experience and has not considered the possibility that coercive parenting may continue or abate as children begin to mature. This is unfortunate since there is evidence to suggest that harsh parenting and its deleterious effects continue into adolescence. Specifically, researchers have found that harsh parenting experienced during adolescence exerts stronger effects on outcomes of delinquency and offending measured in adolescence and young adulthood relative to harsh parenting experienced solely during early childhood [64, 65]. This reinforces the need for examining harsh parenting and its association with antisocial behavior during the developmental periods of adolescence and young adulthood. 
Further, as previously noted, as offspring age, move out of the parental home, and gain firsthand experience of adult life, some perspective may be gained that allows for a "mellowing" in how adult children view childhood experiences, and parents themselves [24]. Thus, a direct "hook" for change (e.g., employment, marriage) may not be a prerequisite for desistance from antisocial behavior. Instead, the evolution of the parentchild relationship itself may exert a positive influence on the individual's trajectory. As children move through adolescence and into young adulthood, there is increased demand for autonomy and independence from parents. How parents respond to these shifts in the parent-child relationship will largely inform future relationship quality [56]. Youth who have experienced a pattern of negative interactions with parents may draw on their increased adult agency to create distance between themselves and their family of origin (Padilla-Walker et al. 2014). This may reduce conflict, but also means there are likely to be reduced opportunities for accessing parental support.

Accordingly, we expect that shifting levels of attachment will be associated with variations in involvement in antisocial behavior, as (1) increased attachment reduces the negative emotionality that may have been associated with some "rebellious" acts, and (2) improved relationships (i.e., less harsh parenting) provide a path to tangible and emotional supports. In contrast, parents' continuing or escalating pattern of reliance on harsh parenting and deteriorating parent-child relationships may be implicated in their children's continued antisocial behavior involvement across the transition period.

\section{Parenting, Identity, and Antisocial Behavior}

Support and control are important dimensions of parenting, but social learning theories have also underscored that the parent's own behavior profile "matters." Numerous studies have shown evidence of intergenerational continuity in antisocial behavior, and thus a comprehensive treatment of parenting effects requires attention to the parent's behavior and orientation [20,22]. Parents serve as key models, and also continually communicate attitudes and worldviews that may increase the likelihood that the child will exhibit aggressive tendencies or become involved in other forms of delinquency. Yet situating social learning processes within a symbolic interactionist framework allows for consideration of how parents influence child behavior through processes related to self and identity. This adds an important dimension to a straightforward learning framework, as research has demonstrated that intergenerational continuity is not inevitable [63]. Thus, variations in developing identities are potentially important mediators and sources of variation, even where parental antisocial behavior is a feature of the child's background and experience.

Although modeling and specific "definitions favorable to the violation of law" may be features of the family environment [60, 68], and the learning of definitions [28, 43], symbolic interactionism stresses that (1) learning continues throughout the life course, (2) individuals are not passive recipients of these experiences and definitions, and (3) over time, identities take shape that give greater coherence to these definitions or alternatively develop in contrast to them [45].

Thus, identities may serve as an important mechanism that links parental influence to behavioral outcomes such as antisocial behavior, or that anchor a path that diverges from that of the parent. In addition, consistent with Cooley's [17] notion of the "looking glass self," children who perceive parents as warm and supportive are more likely to 
develop positive views of themselves. Consequently, identities shaped through parentchild interaction may serve as a cognitive filter as the child encounters contextual changes associated with moving into new adult roles. How an individual "sees oneself" has the potential to influence not only the adoption and expression of these roles but also receptivity to antisocial companions and opportunities, all of which ultimately provide shape and form to an individual's trajectory of antisocial behavior over time. Thus, while traditional parenting factors such as closeness, support, and monitoring may serve to shape children's perceptions of themselves, parents may influence identity formation directly through their own behaviors that include not only coercive practices but also their antisocial behavior profiles. For example, Simons et al. [58] argued that parents are uniquely positioned to influence child attitudes, emotions, and beliefs through both deliberate and unintentional means. They found that parents who are hostile and rejecting, and are antisocial themselves are more likely to have children involved in delinquent behavior.

Matsueda [42] has argued that parents potentially play a central role in which negative and positive self-attributions are adopted by offspring. Because parents themselves may endorse conventional stereotypes of who commits deviant acts, parents who have past histories of problematic behavior may be more prone to communicate negative information to offspring relative to more prosocial parents. Such negative information may not only consist of problematic labels such as the "troublemaker" identity described by Matsueda, but also involve communications that convey the degree of importance that parents assign relationships with their child. Qualitative work by Giordano [22] has highlighted some of these indirect transmission processes, with parents often unintentionally conveying negative messages to offspring in an effort to avoid history repeating itself. Unfortunately, irrespective of parents' best efforts, youth often adopt identities they directly associate with the parents' own deviant history. This is illustrated in the quote below from a respondent in the Giordano study.

“'Cause we're so much alike. I don't know. 'Cause I'm exactly how she was when she was my age. Partying and... Neither one of us liked to go to school. I don't know. We're just exactly the same. Just the way we act. [LaVonda]” ([22], p. 152).

Prior work by Matsueda and Heimer [43] has highlighted how identities crafted through social interaction with others, such as that of a troublemaker, are positively associated with delinquent behavior and contribute to delinquency involvement, net of traditional risk factors. However, identities such as "partier" also vary and may influence behavioral trajectories. For example, numerous studies have documented strong connections between crime and substance use, and thus the party orientation, while not specifically criminal, may be linked to increased receptivity to routine activities and affiliations that make delinquency and crime more likely. To date, researchers have not yet considered the role of parents in relation to the development of identities such as troublemaker and partier, nor explored the impact of variations over time in adoption of these self-views. Thus, we determine whether parents' own early antisocial behavior and parenting practices is associated with increases in offspring's negative identities and delinquent behavior over time and whether these associations operate indirectly through identities. 


\section{The Current Study}

This study will build on developmental and life course criminology perspectives to examine the ways that parents shape trajectories of antisocial behavior from adolescence to young adulthood. In the current study, we examine both between-person and within-person variations in antisocial behavior. This work moves beyond prior studies by focusing on the antisocial behavior of parents and their children, but also considers the pathways through which parents influence their children. We hypothesize the following: (1) the average trajectory among youth whose parents report a history of delinquency during adolescence will be higher than the average trajectory of those youth whose parents do not report any adolescent delinquency; (2) attachment and harsh parenting will not only distinguish between trajectories, but improvements and declines in the quality of attachment and harsh parenting will correspond to change in antisocial behavior trajectories (within-person variation), controlling for unmeasured heterogeneity; and (3) parent's history of adolescent delinquency will influence trajectories of antisocial behavior indirectly through the child's adoption of an antisocial identity (troublemaker, partier).

\section{Methods}

We analyze data from the TARS, using self-reports of antisocial behavior from more than 1300 respondents collected at five time points over an 11-year period that spans the life course stages of adolescence and young adulthood. We rely on multilevel models using HLM 7.01 [52] for our analyses. Time-varying parenting variables are drawn from respondents' self-reports, while time-stable variables, including parents' early antisocial behavior and some background demographic measures, are drawn from the parent questionnaire administered at the first interview (separately from the child interview). Measures relating to identity, changes to social context associated with the transition to adulthood, and additional demographic measures are from respondents' self-reported data. Our longitudinal analyses are aimed at tracing the developmental patterns associated with the parent-child relationship and how these are related to patterns of antisocial behavior across adolescence and into early adulthood. This will provide additional information on the continuing influence of parents even as new sources of influence enter the picture.

\section{TARS Data}

This research draws on data from the TARS, which is based on a stratified random sample of 1321 adolescents and their parents/guardians. A central aim of the study is to examine the nature and meaning of adolescent relationship experiences (e.g., family, peers, and dating partners), and how these experiences associated with age influence the meaning of dating relationships. The TARS data were collected in the years 2001, 2002, 2004, 2006, and 2011. Analyses for the current study rely on structured interviews conducted at waves 1 through 5. The sampling frame of the TARS study encompassed 62 schools across seven school districts. The initial sample was drawn from enrollment records for 7th, 9th, and 
11th grades, but school attendance was not a requirement for inclusion in the study, and most interviews were conducted in the respondent's home using preloaded laptops to administer the interview. This is a significant advantage of using TARS in that youth engaged in antisocial behavior are more likely to not attend school [29, 33]. The stratified, random sample was devised by the National Opinion Research Center and includes oversamples of Black and Hispanic adolescents. Based on 2000 Census data, the sociodemographic characteristics of Lucas County closely parallel those of the nation in terms of race (13\% in Toledo and $12 \%$ in the USA are Black), education ( $80 \%$ in Toledo and $84 \%$ in the USA are high school graduates), median income (\$50,046 in Toledo and $\$ 50,287$ in the USA), and marital status $(73.5 \%$ in Toledo and $75.9 \%$ in the USA are married couple families). The initial sample included 1316 respondents. Retention rates from the first interview were $89.1 \%$ for the second interview, $84.4 \%$ for the third interview, $82.8 \%$ for the fourth interview, and $77.8 \%$ for the fifth interview. Respondents' ages ranged from 12 to 19 years of age at wave 1,13 to 20 years of age at wave 2, 15 to 22 years of age at wave 3, 17 to 24 years of age at wave 4, and 22 to 29 years of age at wave 5. Sixty-two percent of respondents identify as non-Hispanic White, $25 \%$ as non-Hispanic Black, $11 \%$ as Hispanic, and $2 \%$ as some other race/ethnicity. Respondents who identify as something other than White, Black, or Hispanic $(n=26)$ were 12 years of age at wave 1 $(n=20)$ or 29 years of age $(n=16)$, and otherwise had insufficient data $(n=12)$, were deleted from the analytic sample. Thus, for the current analyses, the data reflects an 11-year longitudinal design across five time periods, spanning the ages of 13 to 28 years of age ( $n=1242$ subjects, 5198 observations).

Additionally, parents were administered a paper questionnaire at wave 1 . The majority of those completing the questionnaire were female $(90 \%)$ and/or the biological mother of the respondent $(82 \%)$. Early analyses that included dichotomous variables of the gender and relation of the parent filling out the questionnaire to the respondent revealed that neither of these factors emerged as a significant predictor of the outcomes of interest. Consequently, these items were dropped from the present analyses.

\section{Missing Data}

HLM is able to use any available data at the within-person level; however, data at the between-person level must be complete. Given the small number of missing data at the between-person level $(n=12)$, and that this constituted less than $1 \%$ of the sample, we deleted these cases from the analytic sample. Attrition analyses revealed that respondents who were female, White, reported less structural disadvantage, and growing up in a two biological parent home were more likely to have participated in all five waves. Wave participation rates, however, were not related to wave 1 measures of delinquency, parental support, harsh parenting, parent's early antisocial behavior, or identity endorsement.

\section{Measures}

\section{Dependent Variable (Time-Varying)}

Antisocial behavior is measured using nine items adapted from the 26-item inventory by Elliot and Ageton [19]. Items assess how frequently the respondents 
engaged in various antisocial behaviors including drug use, theft (minor and major), breaking and entering, assault and battery, property damage, selling drugs, public drunkenness, and carrying a hidden weapon. The responses for each item range from 0 for never, to 8 for more than once a day. Alpha scores assessing internal reliability as a latent construct for each wave ranged from 0.74 to 0.88 . However, scales constructed from the mean or sum of inventories of delinquent items produce a measure that is "limited, discrete, and skewed rather than unbounded, continuous, and symmetric" ([49], p. 270). Additionally, such scales assign equal weight to all items. Thus, frequent positive responses to minor offenses such as public drunkenness are treated the same as more serious and less frequent offenses such as breaking and entering. This may obscure effects of certain causal factors relevant to more antisocial respondents because their estimates are swamped by the high frequency of reports of minor offenses by less antisocial offenders [12]. To address these problems, we use a multivariate, multilevel Rasch model that employs a measurement model of self-reported antisocial behavior. This is described in greater detail in the section on analytic strategy.

\section{Parental Behavior (Time-Stable)}

Parent's early antisocial history is assessed using a four-item scale (alpha=0.62). ${ }^{1}$ Parents were asked if the following occurred during their teen years: (1) "I was suspended or expelled from school," (2) "I was arrested by the police," (3) "I drank alcohol," and (4) "I used drugs." Because mothers completed the parent questionnaire $90 \%$ of the time, the scale is skewed to the right. Additionally, fathers reported higher rates on all four items. Among mothers, $13.6 \%$ reported being suspended or expelled, $4.2 \%$ being arrested, $37.4 \%$ drinking alcohol, and $22.6 \%$ using drugs during their teen years. Rates for fathers were $24.2 \%$ for suspension or expulsion, $12.5 \%$ for arrest, $59.4 \%$ for alcohol use, and $31.2 \%$ for drug use. Given the skewed nature of the variable, we created a dichotomous measure coded as 1 for parents who reported any delinquent behavior (47\%) and 0 otherwise.

\section{Identity (Time-Varying)}

Respondents were asked at each wave about a number of identity statuses (e.g., sexy, popular) and to what extent others would describe them in this manner (see especially [42]). Troublemaker identity is assessed at each wave from an item, which asked respondents to what extent others would describe them as: "a troublemaker." Similarly, partier identity is a time-varying measure derived from an item, which asked respondents to what extent others would describe them as "a partier." Responses for both measures range from 1 for strongly disagree to 5 for strongly agree. The troublemaker identity has a mean of 2.23 , with a standard deviation of 1.03 , and the partier identity has a mean of 2.95 and a standard deviation of 1.18 .

\footnotetext{
${ }^{1}$ While parent's early antisocial history displays a low alpha, it should be noted that Cronbach's alpha represents the lower bound of true reliability (Cortina 1993). Additionally, Cortina notes that low alpha scores may simply reflect the low number of items used. Given that the current scale only employs four items, the addition of more items would likely increase its coefficient alpha bringing it within the traditionally accepted range of $>0.70$.
} 


\section{Parenting (Time-Varying)}

Parental support is a mean scale constructed of items used in prior research $[25,30]$ to assess the parent-child bond. Respondents were asked how much they agreed or disagreed with the following statements: (1) "My parents give me the right amount of affection," (2) "My parents trust me," (3) "I'm closer to my parents than a lot of people my age," (4) "I'm close to my parents." (5) "My parents sometimes put me down in front of other people," and (6) "My parents seem to wish I were a different type of person." Items 5 and 6 were reverse coded to reflect higher levels of support. Two additional items, (7) "I rely on my parents for advice," and (8) "I can always count on my parents to help me out financially if the need arises," were included at wave 5 to assess the changing nature of parental support during early adulthood. Responses range from 1 for strongly disagree to 5 for strongly agree, with a mean of 4.03, and a standard deviation of 0.67 . Alpha scores for this measure across the five waves ranged from 0.77 to 0.85 .

Harsh parenting is a mean scale of three items from the Conflict Tactics Scale. Respondents were asked "When you and your parents disagree about things, how often do they do the following" (1) "Call you names or insult you?" (2) "Push, slap or hit you?" and (3) "Yell at you?" For waves 1 through 4, responses ranged from 1 for never to 6 for two or more times a week. At wave 5, responses ranged from 1 for never to 5 for very often. We standardized the responses and used the $z$-scores to construct the scales for each wave with a mean of 0 and a standard deviation of 1 . Aggregated across waves, the measure has a mean of -0.01 and a standard deviation of 0.99 . Alpha scores ranged from 0.66 to 0.72 .

\section{Contextual Variables (Time-Varying)}

A number of time-varying measures that assess gainful activity, living circumstances, time spent with peers, parenthood, and intimate involvement are also included. Gainful activity is coded as 1 (92\% of observations) if the respondent is attending school or employed full-time. Respondents who are not engaged in either activity are coded as 0 .

Living independently is a binary variable coded as 0 for youth who continue to reside in the parental home, and 1 for those who live outside the parental home. Twenty percent of observations across the four waves are coded as living away from home; however, it should be noted that at wave 4, $60 \%$ of respondents reported living away from home.

Time spent with peers is assessed with a single item, which asked respondents, "During the past week how many times did you hang out with your friends?" Responses were 1 for "not at all," 2 for " 1 or 2 times," 3 for " 3 or 4 times," and 4 for "5 or more times." An ANOVA analysis (results not shown) comparing delinquency scores among the four response patterns revealed that only the uppermost response of "5 or more times" differed significantly from the other responses. Thus, there was no detectable difference in delinquency among respondents who scored 1, 2, or 3 on this measure, while those who scored a 4 were significantly different from all other respondents. Consequently, we created a dichotomous measure such that frequent time spent with peers was coded as 1 for respondents who answered "5 or more times" (40\% of all observations), and 0 otherwise. 
Parenthood assesses whether there are children present in the home. These may be the respondent's biological children or non-related children of the partner. Those who report having any children (20\% of all observations) are coded 1 and 0 otherwise.

Relationship type is assessed by creating a series of dichotomous variables for single (15\%), dating (64\%), cohabiting (14\%), and married (7\%). Married is used as the

Table 1 Descriptive statistics for time-varying and time-stable covariates

\begin{tabular}{|c|c|c|c|c|c|c|}
\hline & Mean/Pct $S$ & Std. dev. & Mean/Pct & Std. dev. & Mean/Pct & Std. dev. \\
\hline Time-varying $(n=5285)$ & \multicolumn{2}{|c|}{$\begin{array}{l}\text { Total sample } \\
100.0 \%\end{array}$} & \multicolumn{2}{|c|}{$\begin{array}{l}\text { Youth w/ delinquent } \\
\text { parents } \\
47.5 \%\end{array}$} & \multicolumn{2}{|c|}{$\begin{array}{l}\text { Youth w/ } \\
\text { non-delinquent } \\
\text { parents } \\
52.5 \%\end{array}$} \\
\hline Age $($ range $=13-28)$ & 18.90 & 3.91 & $18.78 *$ & 3.90 & 19.00 & 3.92 \\
\hline Troublemaker identity $($ range $=1-5)$ & 2.17 & 1.01 & $2.24 * * *$ & 1.03 & 2.10 & 0.99 \\
\hline Partier identity (range $=1-5$ ) & 2.83 & 1.20 & $2.88^{* *}$ & 1.20 & 2.78 & 1.20 \\
\hline Parental support (range $=1-5$ ) & 4.04 & 0.66 & $4.02 *$ & 0.65 & 4.06 & 0.66 \\
\hline Harsh parenting (range $=-1.14$ to 7.35$)$ & -0.01 & 0.99 & $0.04 * *$ & 0.99 & -0.05 & 0.10 \\
\hline Gainful activity & 0.80 & & $0.82 *$ & & 0.79 & \\
\hline Lives away from home & 0.29 & & 0.30 & & 0.28 & \\
\hline Frequent time w/peers & 0.34 & & $0.36^{* *}$ & & 0.33 & \\
\hline Parenthood & 0.15 & & $0.14^{*}$ & & 0.16 & \\
\hline \multicolumn{7}{|l|}{ Relationship type } \\
\hline Single & 0.16 & & 0.15 & & 0.16 & \\
\hline Dating & 0.68 & & 0.67 & & 0.68 & \\
\hline Cohabiting & 0.11 & & 0.12 & & 0.11 & \\
\hline Married & 0.06 & & 0.06 & & 0.05 & \\
\hline Current relationship & 0.58 & & 0.58 & & 0.57 & \\
\hline Time-stable $(n=1242)$ & $\begin{array}{l}\text { Total sampl } \\
100.0 \%\end{array}$ & & $\begin{array}{l}\text { Youth w/ d } \\
\text { parents } \\
47.9 \%\end{array}$ & delinquent & $\begin{array}{l}\text { Youth w/ } \\
\text { non-deli } \\
\text { parents } \\
52.1 \%\end{array}$ & nquent \\
\hline Female & 0.52 & & 0.52 & & 0.51 & \\
\hline \multicolumn{7}{|l|}{ Race/ethnicity } \\
\hline White & 0.64 & & $0.70 * * *$ & & 0.58 & \\
\hline Black & 0.25 & & $0.19 * * *$ & & 0.30 & \\
\hline Hispanic & 0.12 & & 0.11 & & 0.12 & \\
\hline Structural disadvantage $($ range $=0-4)$ & 1.28 & 1.24 & 1.26 & 1.18 & 1.29 & 1.29 \\
\hline \multicolumn{7}{|l|}{ Family structure at W1 } \\
\hline Two biological-parent & 0.50 & & 0.48 & & 0.53 & \\
\hline Single parent & 0.26 & & 0.25 & & 0.27 & \\
\hline Step-parent & 0.17 & & $0.23 * * *$ & & 0.12 & \\
\hline Other living arrangement & 0.06 & & $0.05^{*}$ & & 0.08 & \\
\hline
\end{tabular}

Source: Toledo Adolescent Relationships Study

$* p<0.05 ; * * p<0.01 ; * * * p<0.001$ (significantly different from youth $\mathrm{w} /$ non-delinquent parents) 
contrast category because prior research has emphasized the importance of marriage for criminal desistance. Current relationship is a dichotomous variable measured at each wave and coded as 0 for those who are not currently dating, cohabiting, or married, and 1 for those with a current intimate partner (52\% of observations).

\section{Demographic and Background Characteristics (Time-Stable)}

Gender is a dichotomous variable with male (48\%) as the contrast category. Race and ethnicity is composed of White non-Hispanic (63\%), Black non-Hispanic (25\%), and Hispanic (12\%). Dichotomous variables are created for each race/ethnic category, with White as the contrast category.

Disadvantage is measured at wave 1 using four items from the parent survey. Items refer to parents who reported less than 12 years of education, receiving government assistance for needy families (e.g., TANF, food stamps, or a housing subsidy), not having enough money to make a meal in the past 12 months, and unemployment as a "problem" in their neighborhood. The content of these items is consistent with previous work that suggests measuring socioeconomic status with educational, economic, and neighborhood indicators [34]. These items were summed into an index of disadvantage which ranges 0 to 4 , with a mean of 1.28 and a standard deviation of 1.24.

Family structure is composed of four dichotomous variables indicating the household type in which the respondent reported living in during their adolescence at wave 1 . The classifications are two biological-parent $(50 \%)$, single parent $(26 \%)$, step-parent $(18 \%)$, and other $(7 \%)$ at wave 1 . Dichotomous variables are created with "two biological-parent" households as the contrast category (Table 1).

\section{Analytic Strategy}

For the following analyses, we employ hierarchical linear models (HLM) that nest observations over the five time periods within individuals. The current analyses use a three-level model where the first level constitutes a measurement model that estimates each individual's score at each wave on a latent scale of self-reported antisocial behavior, while level 2 is the change model, and level 3 represents the betweenindividual differences.

To differentiate between-person effects from within-person change, the values for time-varying covariates in the level two equation were group-centered; that is, values are transformed into deviations from each individual's mean calculated across all periods of observation [31]. Additionally, at level three, a person-level mean for each time-varying measure is included. Thus, individuals serve as their own control, thereby increasing confidence that between-person differences are not contaminating the assessment of within-individual change. This process also assists in assessing mediating processes in multilevel models, particularly across levels, with respect to untangling within-group and betweengroup effects [69]. In the mediational analyses, we focus on the person-level mean of the identity process (level 3 variable) as the mediator of the link between parent's early antisocial behavior and the outcome of interest. We provide a description of our statistical model in greater detail below. 


\section{Statistical Model for Antisocial Behavior}

Level 1 constitutes a measurement model of antisocial behavior that draws on item response theory (IRT). Rather than a simple sum of the individual items measuring antisocial behavior, IRT relies on mathematical models that estimate theta $(\theta)$, which represents a latent trait of interest, such as antisocial behavior [49]. A respondent's position on $\theta$ is inferred by the following equation:

$$
\eta_{i j k}=\pi_{j k}+\psi_{i}
$$

where $\eta$ represents the log-odds of a positive response to item $i$, for respondent $k$, at wave $j, \pi_{j k}$ signifies each individual's general likelihood of offending at a particular wave, and $\psi_{i}$ represents the severity of each item.

The level 1 model constitutes the measurement model that estimates $\psi_{i}$. Each of the nine items that comprise the scale of antisocial behavior were dichotomized such that respondents who reported having engaged in that behavior regardless of the frequency were scored 1 and were scored 0 if they reported not having engaged in the behavior. A person period file is then constructed that situates persons within waves, which are then situated in a set of sub-observations, or cases, consisting of the nine latent trait items. The severity estimates represent the mean rates of response for each item across all five waves for the full sample. The mean likelihood to engage in antisocial behavior for any individual at a given wave $(\pi 0 j k)$ is modeled as:

$$
\pi 0 j k=\mu+X j k \beta+W k \gamma
$$

where $\mu$ is the model intercept, $X j k$ is a vector of time-varying covariates for each respondent $(k)$ at each wave $(\mathrm{j})$, and $W k$ represents a vector of time-stable covariates for each respondent.

The level 2 model (Eq. 3) holds item responses constant across persons, but allows individual propensities, $\pi j k$, to vary as a function of the mean person

Table 2 Items and severity coefficients from measurement model $(N=46,760)$

\begin{tabular}{lllll}
\hline Variable & Pct. & Severity coefficient & Odds ratio & S.E. \\
\hline Intercept & & -0.89 & 0.41 & 0.04 \\
Been drunk in a public place (excluded) & $34.05 \%$ & & & \\
Used drugs & $23.0 \%$ & -0.42 & 0.66 & 0.04 \\
Attacked someone & $9.2 \%$ & -1.35 & 0.26 & 0.06 \\
Stolen things worth \$5 or less & $7.8 \%$ & -1.56 & 0.21 & 0.06 \\
Sold drugs & $6.8 \%$ & -1.79 & 0.17 & 0.07 \\
Damaged or destroyed property & $6.5 \%$ & -1.62 & 0.20 & 0.06 \\
Carried a hidden weapon & $5.4 \%$ & -2.02 & 0.13 & 0.08 \\
Stolen things worth $\$ 50$ or more & $3.0 \%$ & -2.49 & 0.08 & 0.08 \\
Broken into a building or vehicle & $2.8 \%$ & -2.53 & 0.08 & 0.08 \\
\hline
\end{tabular}

Source: Toledo Adolescent Relationships Study 
propensity over the five wave period $k, \beta 0 k$, individual-level covariates $X 1 k, \ldots$ $X n k$, and $r_{o}$ represents any unexplained variance.

$$
\pi j k=\beta 0 k+\beta 1 k X 1 k+\ldots+\beta n k X n k+r_{o}
$$

The level 3 model (Eq. 4) allows person mean propensities, $\beta 0 k$, to vary as a function of the grand mean propensity to antisocial behavior in the sample, $\gamma$, and a random effect $\nu_{\mathrm{k}}$.

$$
\beta 0 k=\gamma+\nu_{k}
$$

Table 2 provides the percentage of cases with positive responses on each antisocial behavior item, as well as its accompanying severity coefficient and odds ratio. These numbers were derived by running the measurement model prior to the inclusion of any other covariates, while excluding one of the items from the model to act as the referent, in this case public drunkenness. Thus, severity coefficients and odds ratios refer to the probability that the behavior is reported relative to public drunkenness. Consequently, items with a higher percentage constitute behaviors that are engaged in more frequently by the sample, while those with a lower percentage are items that occur with less frequency and thus are theorized to be more severe. Within the TARS sample, alcohol and drug use stand out as the two behaviors in which respondents are most likely to report, while carrying a hidden weapon, breaking and entering, and stealing something valued over $\$ 50$ are the behaviors least likely to be reported.

\section{Results}

To assess model fit, an intercept-only model was run to obtain the intraclass correlation (ICC). Results reveal an ICC of $0.495(2.13 / 2.13+2.17)$ indicating the variance was virtually evenly split at the between- and within-person levels. We considered whether growth patterns (slope) varied randomly across individuals by including random effects for each of the age terms; however, these were non-significant. Consequently, we chose to include a random effect for only the intercept in each of the models.

Below, we present results from the Rasch models examining parenting and antisocial behavior across adolescence and young adulthood (Table 3). The purpose of these analyses is to assess whether (1) trajectories of antisocial behavior among youth vary based on parent's history of adolescent delinquency; (2) changes in the parent-child bond and parenting practices correspond to within-person change in antisocial behavior trajectories, net of any between-person differences; and (3) parent's delinquency exerts a direct effect on between-person differences in antisocial behavior or operates primarily indirectly through identity processes. With the exception of the unconditional growth model, we control for gender, race/ethnicity, structural disadvantage, and family structure during adolescence.

Model 1 presents the results for the unconditional growth models of antisocial behavior among youth with delinquent and non-delinquent parents. Since nondelinquent parents are the reference, and age is centered at 13 years, the age coefficients represent the effect for a 13-year-old youth with non-delinquent parents. Both age and 


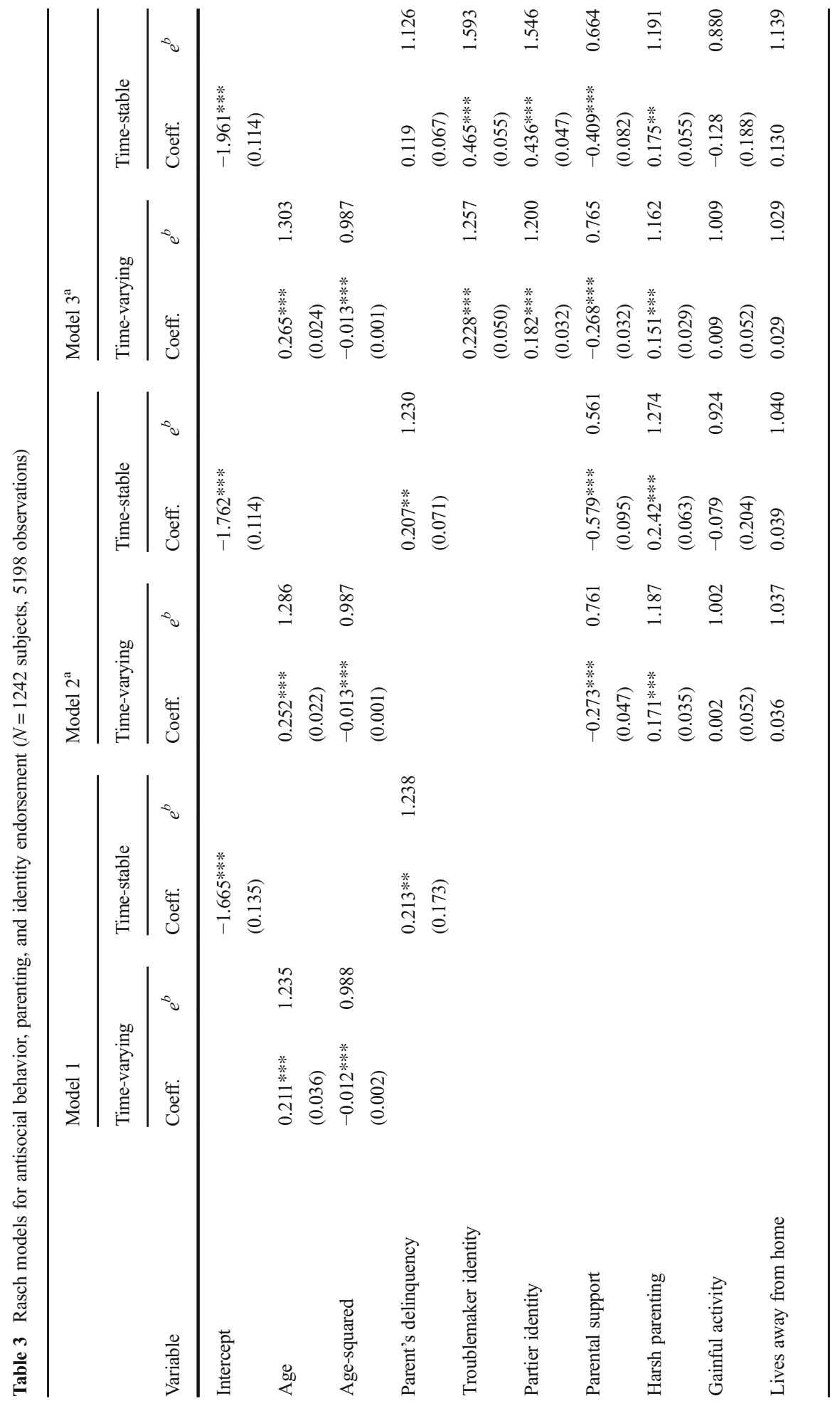




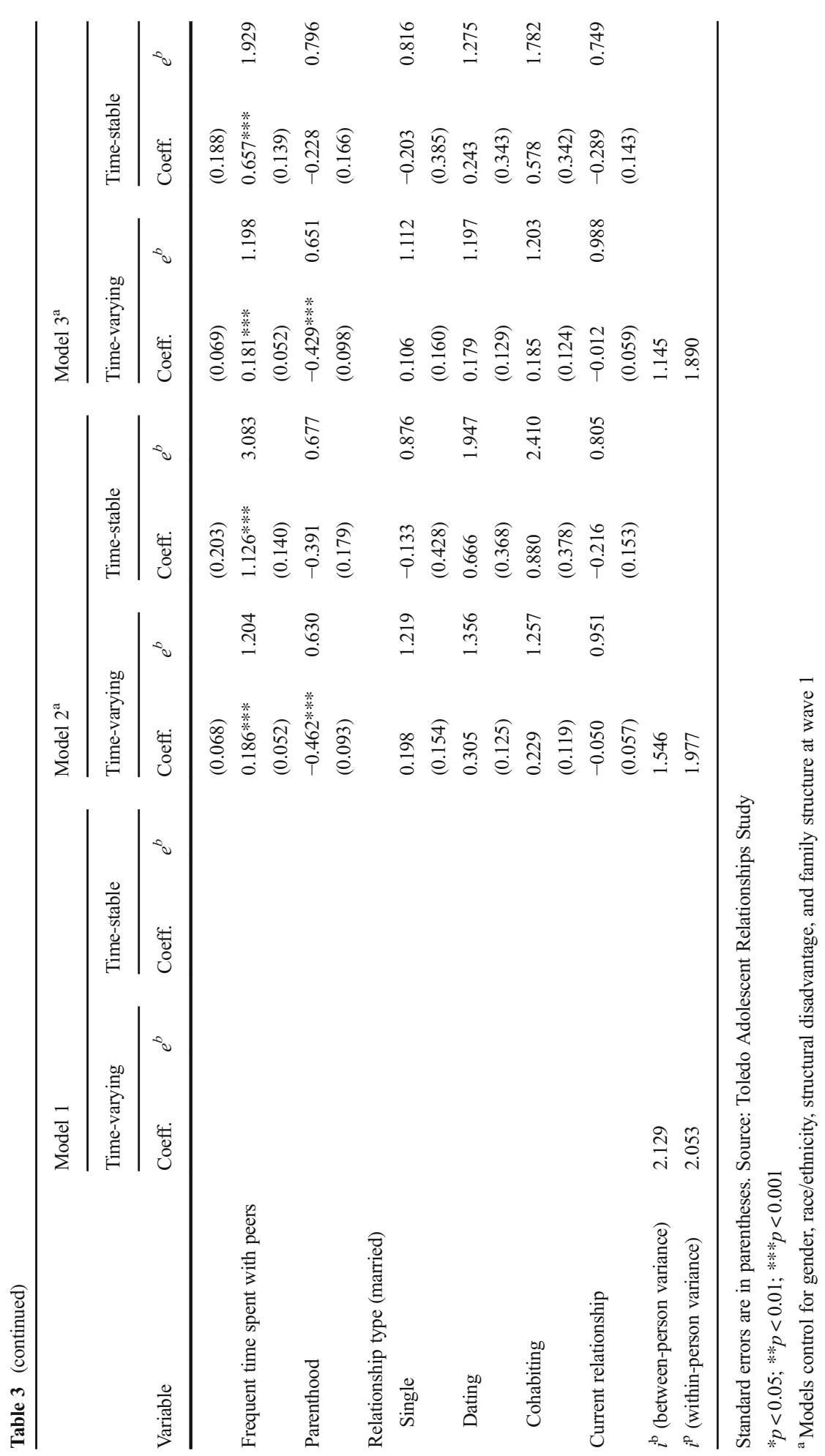


age-squared were significant indicating a curvilinear relationship. The effect for parent's delinquency was positive and significant, while the interactions with age were not. 2 This suggests that while trajectories of antisocial behavior for youth in both groups follow a fairly typical age curve that peaks during the late teens, trajectories for youth with delinquent parents are, on average, higher compared to those with non-delinquent parents.

Model 2 introduces parental support and harsh parenting along with the time-varying and time-stable controls. Consistent with our second set of hypotheses, variations in parental support and harsh parenting not only distinguished between trajectories of antisocial behavior but also corresponded to within-person changes in antisocial behavior. An increase of 1 standard deviation above the individual mean in parental support, corresponded to a $24 \%$ decrease in the odds of antisocial behavior $\left(e^{b}=0.761\right.$, $p<0.001)$. Conversely, an increase of 1 standard deviation above the individual mean in harsh parenting corresponded to a $19 \%$ increase in the odds of antisocial behavior $\left(e^{b}=1.187, p<0.001\right)$. The between-person effects indicate that as the individual mean scores increased by 1 standard deviation above the grand sample mean, this corresponded to a $44 \%$ decrease in the odds of antisocial behavior for parental support $\left(e^{b}=0.561, p<0.001\right)$ and a $27 \%$ increase in the odds of antisocial behavior for harsh parenting $\left(e^{b}=1.274, p<0.001\right)$. Additionally, frequent time spent with peers and parenthood was associated with antisocial behavior at both the between- and withinperson levels. The variables in model 2 accounted for approximately $27 \%$ of the variance at the between-person level (2.129-1.546/2.129) and approximately $4 \%$ of the variance at the within-person level (2.053-1.977/2.053) compared to the unconditional growth model. Notably, none of the variables, including the traditional parenting variables, attenuated the effects of parent's delinquency, highlighting the need to consider processes beyond support and control.

Model 3 assessed whether the identity endorsements mediated the relationship between parent's delinquency and antisocial behavior at the between-person level. Effects for endorsement of the troublemaker and partier identities were associated with higher odds of antisocial behavior at the both the between- and within-person levels. Individuals with a higher endorsement of the troublemaker identity relative to the sample average showed increased odds of antisocial behavior $\left(e^{b}=1.593, p<0.001\right)$, as did those who endorsed the partier identity $\left(e^{b}=1.546, p<0.001\right)$. Yet, each of the identities also demonstrated fluidity, with increases in endorsement of each identity leading to further increased odds of antisocial behavior (troublemaker- $e^{b}=1.257$, $p<0.001$; partier $\left.-e^{b}=1.200, p<0.001\right)$. Furthermore, the between-person effects of the two identities combined reduced the coefficient for parent's delinquency by $43 \%$, rendering it non-significant. ${ }^{3}$ To assess mediation, we followed the procedures recommended by Zhang et al. [69]. Given our use of the multilevel model and that our between-person variables are grand-mean-centered, we applied a $t$ statistic [21] to test the significance of the reduction in the coefficients after running separate models for each of the identity endorsements. While neither of these fully mediated the effect of parent's delinquency, the $t$ test for each was significant (troublemaker, $t=-14.24$,

\footnotetext{
${ }^{2}$ Parent's delinquency did not interact with age regardless of where the age variables were centered.

${ }^{3}$ Separate models including each identity separately did not fully attenuate the effect of parent's delinquency, but still reduced it by $36 \%$ for the troublemaker identity and $25 \%$ for the partier identity.
} 
$p<0.001$; partier, $t=-35.44, p<0.001$ ), suggesting that each of these independently provided partial mediation of parent's delinquency on antisocial behavior. Additional analyses investigated whether the time-varying effects of parenting or identity endorsement on antisocial behavior differed based on parent's delinquency. These cross-level interactions were not significant.

\section{Discussion}

Parent's delinquency was associated with a higher average trajectory of antisocial behavior, thereby supporting our initial hypothesis. Furthermore, introduction of controls including frequent time spent with peers did little to diminish this association. While frequently spending time with peers is not problematic in itself, it is worth noting that youth who reported hanging out with friends five or more times per week had a higher average score of antisocial behavior compared to those youth who spent less time with friends. Frequent time with friends also demonstrated a strong association with antisocial behavior at both the between- and within-person levels. This suggests that parents' deviant histories exert their own independent effects on offspring behavior. This is in contrast to previous findings by Warr [66] which suggested that parents' influence is primarily indirect through their ability to inhibit association with deviant peers.

Attachment and harsh parenting both influenced within-individual change in antisocial behavior trajectories even after controlling for between-individual differences and the time-varying controls. This supported our second hypothesis and is consistent with developmental and life course perspectives that emphasize malleability in trajectories of behavior. These findings highlight that parents continue to matter beyond adolescence, and that the parent-child bond displays variations over time that influence trajectories of antisocial behavior. Contradictory to Hirschi's [30] hypothesis of delinquent youth having "cold and brittle" relationships, these within-person level findings demonstrate that to the degree youth enjoy an increase in parent-child bond quality, this does correspond to a decrease in levels of antisocial behavior net of potential selection factors.

Endorsement of problematic identities accounts for some of the direct effects of parents' early antisocial history on antisocial behavior trajectories thereby providing partial support for the third hypothesis. These findings suggest that what individuals bring to the task of parenting, in terms of their early history, matters not only in their direct influence on antisocial behavior but also indirectly through the child's own developing identities. However, since the troublemaker and partier identities only partially mediated the effect of parental early antisocial behavior on antisocial behavior, future exploration of additional identity processes is warranted, and the notion of direct transmission should not be discarded.

While this study takes a long view on parenting, there are a few limitations. First, the directionality of the parent-child interactions cannot be discerned. While we depict parenting as influencing offspring's antisocial behavior, it is also possible that the offspring's antisocial behavior influences parenting. Cross-lagged models were considered. Given the time gaps between data points, however, we run the risk of overlooking the influence of more proximal parenting behaviors that would likely have a stronger influence on antisocial behavior. It is likely that parenting and antisocial behavior exert 
reciprocal effects on one another, demonstrating an interactional pattern. Consequently, determining which actor in the parent-child dyad is initiating the change is likely akin to a chicken and egg argument. Previous work by Buist et al. (2004) examined the reciprocal effects of attachment on internalizing and externalizing behaviors among a sample of teens during middle-adolescence over three assessment periods separated by a 1-year gap. Results indicated that influences operated in both directions for both internalizing and externalizing behaviors from time 1 to time 2 . No effects were observed for the lagged relationships from time 2 to time 3 . They note that there was considerable stability in all three measures over the three assessment periods, and particularly from time 2 to time 3 . Their sample, however, was a relatively small $(n=238)$ and homogenous group (two-parent, Dutch origin, middle-class), relative to the more diverse sample used in the current study. Regardless of whose behavior is changing first, improvements or declines in parenting and antisocial behavior are contingent on one dyad member responding (for better or worse) to the behaviors of the other $[7,50]$. Thus, the results of the current study highlight that irrespective of the directionality, parent-child relationships and their association with antisocial behavior remain fluid and dynamic well into adolescence and young adulthood.

Another limitation is that the lack of data from parents across waves creates a heavy reliance on children's reports of the parent-child relationship. Since parental characteristics are only available at wave 1 , mediational analyses must be limited to betweenperson effects that use aggregated means of identity processes and parenting practices. This excludes consideration of how changes in parents' behavior, lifestyle orientation, and identity may be related to changes in their offspring. Previous work examining changes in parent-child relationships [56] shows that while changes in parental support over time tend to be modest, patterns vary across individuals. Thus, there is no "one size fits all" developmental pattern of change. Therefore, a contribution of the current study is that it does identify one indicator (parents' delinquency) potentially responsible for producing variability in trajectories of antisocial behavior via identity endorsements. Given that these identities are malleable, it raises the question of whether differentials in endorsement of the troublemaker or partier identity exist between those whose parents report adolescent delinquency, and those who do not. Youth from homes with antisocial parents may have a more difficult time shaking off the identity relative to their peers with more prosocial parents. Future work examining these mechanisms using more complex and robust measures of both parent and child identities are needed.

Recognizing the dynamic nature of parent-child relationships has important social policy implications. For example, previous studies assessing the efficacy of juvenile drug courts suggest that parental involvement is a critical factor in ensuring success [4, 46]. If the assumption is that success is mainly a by-product of selection, it would suggest that youth with successful outcomes are likely those with consistently supportive parents and may not represent the population in greatest need of intervention. Meanwhile, those most at risk likely do not benefit, which then calls into question the need for such programs at all. In contrast, acknowledging that parent-child relationships are fluid and subject to change highlights that involving parents in juvenile justice interventions is not only beneficial, but necessary to increase successful outcomes even among those at high risk of persistent offending. This is further reinforced by our results showing that the association between parenting and offspring antisocial behavior was similar for youth irrespective of their parents' own delinquent history. 
It is well understood that a key task of late adolescence and young adulthood involves the reorganization and transformation of the parent-child relationship to one that is less hierarchical and one characterized by mutual respect [40]. While sources of social influence outside of the familial circle begin to emerge in the form of peers and intimate partners [37], relationships with parents remain, for better or worse, socially relevant in the lives of individuals [10]. Over the course of adolescence and the transition to adulthood, parents provide an ongoing source of social and material support [53]. While parent-child relationships are likely to demonstrate a considerable amount of continuity over time, there is also evidence that parent-child interactions do change over time [6]. Consequently, there is a continuing need for consideration of parents and the roles that they play in shaping trajectories of wellbeing among their offspring.

The current study represents a step in this direction; however, further research on parent-child relationships across adolescence and young adulthood is warranted. For example, here we have focused primarily on how parents' behavior influences on a particular child outcome. Yet, as children move into adulthood, opportunities for children to operate as sources of social and material support to parents increase. These opportunities provide openings for parent-child dynamics to be altered that could further influence outcomes for offspring, as well as their parents. This is a phenomenon that has been explored more extensively among older adults and their offspring (e.g., [38]), but could well make a difference for understanding transformations in the parentchild relationship as individuals mature into adulthood. Additionally, there is evidence that variations in the paths to adulthood are becoming more numerous and increasingly complex [48]. Thus, greater theoretical attention needs to be given to the ways in which different populations of parents and offspring experience this transitional period. Both parents and offspring will benefit from greater attention given to these issues and the mechanisms that help promote healthier and happier relationships over the life course.

Acknowledgments This research was supported by grants from The Eunice Kennedy Shriver National Institute of Child Health and Human Development (HD036223 and HD044206), the Department of Health and Human Services (5APRPA006009), the National Institute of Justice, Office of Justice Programs, U.S. Department of Justice (Award Nos. 2009-IJ-CX-0503 and 2010-MU-MU-0031), and in part by the Center for Family and Demographic Research, Bowling Green State University, which has core funding from The Eunice Kennedy Shriver National Institute of Child Health and Human Development (R24HD050959-01). Additional support was provided by the Oakland University Research Committee (Award No. 3467).

\section{References}

1. Acs, G. (2007). Can we promote child well-being by promoting marriage? Journal of Marriage and Family, 69, 1326-1344.

2. Addo, F. R. (2014). Debt, cohabitation, and marriage in young adulthood. Demography, 51(5), 1677-1701.

3. Agnew, R. (1985). A revised strain theory of delinquency. Social Forces, 64(1), 151-167.

4. Alarid, L. F., Montemayor, C. D., \& Dannhaus, S. (2012). The effect of parental support on juvenile drug court completion and postprogram recidivism. Youth Violence and Juvenile Justice, 10(4), 354-369.

5. Anderson, A. L., \& Hughes, L. A. (2009). Exposure to situations conducive to delinquent behavior: the effects of time use, income and transportation. Journal of Research in Crime and Delinquency, 46, 5-34. 
6. Aquilino, W. S. (2005). Impact of family structure on parental attitudes toward the economic support of adult children over the transition to adulthood. Journal of Family Issues, 26, 143-167.

7. Aquilino, W. S. (1997). From adolescent to young adult: a prospective study of parent-child relations during the transition to adulthood. Journal of Marriage and the Family, 59(3), 670-686.

8. Arnett, J. J. (2000). Emerging adulthood: a theory of development from the late teens through the twenties. American Psychologist, 55(5), 469.

9. Arnett, J. J. (2004). Emerging adulthood: the winding road from the late teens through the twenties. New York: Oxford University Press.

10. Birditt, K. S., Miller, L. M., Fingerman, K. L., \& Lefkowitz, E. S. (2009). Tensions in the parent and adult child relationship: links to solidarity and ambivalence. Psychology and Aging, 24(2), 287.

11. Brauer, J. R., \& De Coster, S. (2015). Social relationships and delinquency: revisiting parent and peer influence during adolescence. Youth \& Society, 47(3), 374-394.

12. Cernkovich, S. A., \& Giordano, P. C. (2001). Stability and change in antisocial behavior: the transition from adolescence to early adulthood. Criminology, 39(2), 371-410.

13. Collins, W. A. (1996). Relationships and development during adolescence: interpersonal adaptation to developmental change. Personal Relationships, 3, 337-351.

14. Collins, W. A. (2003). More than myth: the developmental significance of romantic relationships during adolescence. Journal of Research on Adolescence, 13(1), 1-24.

15. Colvin, M., Cullen, F. T., \& Vander Ven, T. (2002). Coercion, social support, and crime: an emerging theoretical consensus. Criminology, 40(1), 19-42.

16. Conger, R. D., Martin, M. J., Masarik, A. S., Widaman, K. F., \& Donnellan, M. B. (2015). Social and economic antecedents and consequences of adolescent aggressive personality: predictions from the interactionist model. Development and Psychopathology, 27(4pt1), 1111-1127.

17. Cooley, C. H. (1972). Looking glass self. In J. G. Manis \& B. N. Meltzer (Eds.), Symbolic interaction: $a$ reader in social psychology (pp. 231-233). Boston: Allyn \& Bacon.

18. Demuth, S., \& Brown, S. L. (2004). Family structure, family processes and delinquency: the significance of parental absence versus parental gender. Journal of Research in Crime and Delinquency, 41, 58-81.

19. Elliot, D. S., \& Ageton, S. S. (1980). Reconciling race and class differences in self-reported and official estimates of delinquency. American Sociological Review, 45, 95-110.

20. Farrington, D. P. (2011). Families and crime. In J. Q. Wilson \& J. Petersilia (Eds.), Crime and public policy (pp. 130-157). New York: Oxford University Press.

21. Freedman, L. S., \& Schatzkin, A. (1992). Sample size for studying intermediate endpoints within intervention trials of observational studies. American Journal of Epidemiology, 136, 1148-1159.

22. Giordano, P. C. (2010). Legacies of crime: a follow-up of the children of highly delinquent girls and boys. New York: Cambridge University Press.

23. Giordano, P. C., Cernkovich, S. A., \& Holland, D. D. (2003). Changes in friendship relations over the life course: implications for desistance from crime. Criminology, 41(2), 293-328.

24. Giordano, P. C., Schroeder, R. D., \& Cernkovich, S. A. (2007). Emotions and crime over the life course: a neo-Meadian perspective on criminal continuity and change. American Journal of Sociology, 112(6), 1603-1661.

25. Gold, M., \& Reimer, D. J. (1975). Changing patterns of delinquent behavior among Americans 13 through 16 years old: 1967-1972. Crime and Delinquency Literature, 7(4), 483-517.

26. Gottfredson, M., \& Hirschi, T. (1990). A general theory of crime. Stanford, CA: Stanford University Press.

27. Hamilton, S. F., \& Hamilton, M. A. (2006). School, work, and emerging adulthood. In J. J. Arnett \& J. L. Tanner (Eds.), Emerging adults in America: coming of age in the 21st century (pp. 257-277). Washington: American Psychological Association.

28. Heimer, K., \& DeCoster, S. D. (1999). The gendering of violent delinquency. Criminology, 37(2), 277-318.

29. Henry, K. L., Knight, K. E., \& Thornberry, T. P. (2012). School disengagement as a predictor of dropout, delinquency, and problem substance use during adolescence and early adulthood. Journal of Youth and Adolescence, 41(2), 156-166.

30. Hirschi, T. (1969). Causes of delinquency. Berkeley: University of California Press.

31. Horney, J., Osgood, D. W., \& Marshall, I. H. (1995). Criminal careers in the short-term: intra-individual variability in crime and its relation to local life circumstances. American Sociological Review, 60(5)655673.

32. Jang, S. J. (1999). Age-varying effects of family, school, and peers on delinquency: a multilevel modeling test of interactional theory. Criminology, 37(3), 643-686. 
33. Kearney, C. A. (2008). An interdisciplinary model of school absenteeism in youth to inform professional practice and public policy. Educational Psychology Review, 20(3), 257-282.

34. Krieger, N., Williams, D. R., \& Moss, N. E. (1997). Measuring social class in US public health research: concepts, methodologies, and guidelines. Annual Review of Public Health, 18(1), 341-378.

35. Laub, J. H., \& Sampson, R. J. (1993). Turning points in the life course: why change matters to the study of crime. Criminology, 31(3), 301-325.

36. Laub, J. H., \& Sampson, R. J. (2003). Shared beginnings, divergent lives: delinquent boys to age 70. Cambridge: Harvard University Press.

37. Laursen, B., \& Williams, V. A. (1997). Perceptions of interdependence and closeness in family and peer relationships among adolescents with and without romantic partners. New Directions for Child and Adolescent Development, 1997(78), 3-20.

38. Lin, I. F. (2008). Mother and daughter reports about upward transfers. Journal of Marriage and Family, 70(3), 815-827.

39. Loeber, R., \& Farrington, D. P. (1994). Problems and solutions in longitudinal and experimental treatment studies of child psychopathology and delinquency. Journal of Consulting and Clinical Psychology, 62(5), 887-900.

40. Longmore, M. A., Manning, W. D., \& Giordano, P. C. (2013). Parent-child relationships in adolescence. In M. Fine \& F. Fincham (Eds.), Handbook of family theories: a content-based approach (pp. 28-50). New York: Routledge.

41. Martin, J. A., Hamilton, B. E., Osterman, M. J. K., et al. (2015). Births: final data for 2013. National Vital Statistics Reports (Vol. 64(1)). Hyattsville: National Center for Health Statistics.

42. Matsueda, R. L. (1992). Reflected appraisals, parental labeling, and delinquency: specifying a symbolic interactionist theory. American Journal of Sociology, 97(6), 1577-1611.

43. Matsueda, R. L., \& Heimer, K. (1987). Race, family structure, and delinquency: a test of differential association and social control theories. American Sociological Review, 52(6), 826-840.

44. Mathews, T. J., \& Hamilton, B. E. (2014). First births to older women continue to rise. NCHS data brief, no 152. Hyattsville: National Center for Health Statistics.

45. Mead, G. (1934). Mind, self, and society: from the standpoint of a social behaviorist. Chicago: University of Chicago Press.

46. Mericle, A. A., Belenko, S., Festinger, D., Fairfax-Columbo, J., \& McCart, M. R. (2014). Staff perspectives on juvenile drug court operations a multi-site qualitative study. Criminal Justice Policy Review, 25(5), 614-636.

47. Moffitt, T. E. (1993). Life-course-persistent and adolescence-limited antisocial behavior: a developmental taxonomy. Psychological Review, 100(4), 674-701.

48. Osgood, D. W., Ruth, G., Eccles, J. S., Jacobs, J. E., \& Barber, B. L. (2005). Six paths to adulthood: fast starters, parents without careers, educated partners, educated singles, working singles, and slow starters. In R. A. Settersten, F. F. Furstenberg, \& R. G. Rumbaut (Eds.), On the frontier of adulthood: theory, research, and public policy (pp. 225-255). Chicago: The University of Chicago Press.

49. Osgood, D. W., McMorris, B. J., \& Potenza, M. T. (2002). Analyzing multiple-item measures of crime and deviance: item response theory scaling. Journal of Quantitative Criminology, 18(3), 267-296.

50. Padilla-Walker, L. M., Nelson, L. J., \& Knapp, D. J. (2013). "Because I'm still the parent, that's why!" Parental legitimate authority during emerging adulthood. Journal of Social and Personal Relationships, 31(3), 293-313.

51. Pettit, G. S., Laird, R. D., Dodge, K. A., Bates, J. E., \& Criss, M. M. (2001). Antecedents and behaviorproblem outcomes of parental monitoring and psychological control in early adolescence. Child Development, 72(2), 583-598.

52. Raudenbush, S. W., Bryk, A. S., \& Congdon, R. (2004). HLM 6 for Windows [Computer software] (Version 6.08). Lincolnwood: Scientific Software International.

53. Schoeni, R. F., \& Ross, K. E. (2005). Material assistance from families during the transition to adulthood. In R. A. Settersten, F. F. Furstenberg, \& R. G. Rumbaut (Eds.), On the frontier of adulthood: theory, research, and public policy (pp. 396-416). Chicago: The University of Chicago Press.

54. Shanahan, M. J., Porfeli, E. J., Mortimer, J. T., \& Erickson, L. D. (2005). Subjective age identity and the transition to adulthood: when do adolescents become adults? In R. A. Settersten, F. F. Furstenberg, \& R. G. Rumbaut (Eds.), On the frontier of adulthood: theory, research, and public policy (pp. 225-255). Chicago: The University of Chicago Press.

55. Siennick, S. E., Staff, J., Osgood, D. W., Schulenberg, J. E., Bachman, J. G., \& VanEseltine, M. (2014). Partnership transitions and antisocial behavior in young adulthood: a within-person, multi-cohort analysis. Journal of Research in Crime and Delinquency, 51(6), 735-758. 
56. Seiffge-Krenke, I., Overbeek, G., \& Vermulst, A. (2010). Parent-child relationship trajectories during adolescence: longitudinal associations with romantic outcomes in emerging adulthood. Journal of Adolescence, 33(1), 159-171.

57. Simons, R. L., Johnson, C., \& Conger, R. D. (1994). Harsh corporal punishment versus quality of parental involvement as an explanation of adolescent maladjustment. Journal of Marriage and the Family, 56(3), 591-607.

58. Simons, R. L., Simons, L. G., Chen, Y., Brody, G. H., \& Lin, K. (2007). Identifying the psychological factors that mediate the association between parenting practices and delinquency. Criminology, 45(3), 481-517.

59. Singer, J. D., \& Willett, J. B. (2003). Applied longitudinal data analysis. New York: Oxford University Press.

60. Smith, C. A., Ireland, T. O., Park, A., Elwyn, L., \& Thornberry, T. P. (2011). Intergenerational continuities and discontinuities in intimate partner violence: a two-generational prospective study. Journal of Interpersonal Violence, 26(18), 3720-3752.

61. Snyder, J., \& Patterson, G. (1987). Family interaction and delinquent behavior. In H. Quay (Ed.), Handbook of juvenile delinquency (pp. 216-243). New York: Wiley.

63. Straus, M. A., Douglas, E. M., \& Medeiros, R. A. (2014). The primordial violence: spanking children, psychological development, violence, and crime. New York: Routledge.

63. Thornberry, T. P. (2005). Explaining multiple patterns of offending across the life course and across generations. The Annals of the American Academy of Political and Social Science, 602(1), 156-195.

64. Thornberry, T. P., Henry, K. L., Ireland, T. O., \& Smith, C. A. (2010). The causal impact of childhoodlimited maltreatment and adolescent maltreatment on early adult adjustment. Journal of Adolescent Health, 46(4), 359-365.

65. Thornberry, T. P., Ireland, T. O., \& Smith, C. A. (2001). The importance of timing: the varying impact of childhood and adolescent maltreatment on multiple problem outcomes. Development and Psychopathology, 13(4), 957-979.

66. Warr, M. (1993). Parents, peers, and delinquency. Social Forces, 72(1), 248-264.

67. Warr, M. (2005). Making delinquent friends: adult supervision and children's affiliations. Criminology, 43(1), 77-106.

68. Widom, C. S. (1989). The cycle of violence. Science, 244, 160-166.

69. Zhang, Z., Zyphur, M. J., \& Preacher, K. J. (2009). Testing multilevel mediation using hierarchical linear models problems and solutions. Organizational Research Methods, 12(4), 695-719. 